This item was submitted to Loughborough's Research Repository by the author.

Items in Figshare are protected by copyright, with all rights reserved, unless otherwise indicated.

\title{
Enhanced wear performance of laser machined tools in dry turning of hardened steels
}

PLEASE CITE THE PUBLISHED VERSION

https://doi.org/10.1016/j.jmapro.2020.04.058

PUBLISHER

Elsevier

VERSION

AM (Accepted Manuscript)

\section{PUBLISHER STATEMENT}

This paper was accepted for publication in the journal Journal of Manufacturing Processes and the definitive published version is available at https://doi.org/10.1016/j.jmapro.2020.04.058.

LICENCE

CC BY-NC-ND 4.0

\section{REPOSITORY RECORD}

Pacella, Manuela, and Daniel Brigginshaw. 2020. "Enhanced Wear Performance of Laser Machined Tools in Dry Turning of Hardened Steels”. Loughborough University. https://hdl.handle.net/2134/12155208.v1. 


\title{
Enhanced wear performance of laser machined tools in dry turning of hardened steels
}

\author{
Manuela Pacella*a ${ }^{*}$ Daniel Brigginshaw ${ }^{\mathrm{a}}$ \\ ${ }^{\mathrm{a}}$ Wolfson School of Mechanical, Electrical and Manufacturing Engineering, Loughborough \\ University, Loughborough, Leicestershire, LE11 3TU, UK \\ *Corresponding author: M.Pacella@1boro.ac.uk \\ ORCID: 0000-0002-5775-1038 \\ Loughborough University, Epinal Way, Loughborough LE11 3TU
}

\begin{abstract}
Polycrystalline boron nitride cutting tools are currently used for precision machining of automotive components made of hardened steel due to their high wear resistance and long durability, however adhesion of workpiece to the cutting tool can reduce cutting tool lifetime. Laser surface engineering of polycrystalline boron nitride single point cutting tools using a nanosecond fibre laser is proposed to improve their wear properties and extend tool life in turning of continuous hardened steel components.

The effect of different designs on the wear properties was investigated in turning tests under dry conditions and compared to benchmark cutting tools made of the same material.

Condition monitoring of machining forces revealed a $20 \%$ reduction of cutting force and $30 \%$ reduction of feed force for tools with crosshatch design and grooves perpendicular to chip flow direction, when benchmarked to commercial cutting tools.

The number of grooves in contact with the forming chip contributed to the creation of three distinguished interfacial secondary deformation areas. Texturing the chamfer proved to alter the dynamic of chip formation in the secondary deformation zone, while engineering the formation of laser-induced solid lubricant h-BN improved the heat dissipation rate in the secondary and tertiary deformation areas.

To the best of authors' knowledge, this paper reports for the first time the possibility of simultaneously engineer geometry and chemistry of PcBN cutting tools so to enhance their service life by up to $20 \%$.
\end{abstract}

\section{Keywords}

Laser texturing

Turning tools

Polycrystalline boron nitride

Laser ablation

Wear properties

Flank wear

Precision machining

Solid lubricant 


\section{Introduction}

Precision machining industry is dominated by the need of improving performance and reduce costs. These trends are partially driven by new technology development in workpiece material design and favour the use of wear resistant ultra-hard materials such as synthetic polycrystalline diamonds (PCD) and polycrystalline boron nitrides (PcBN). Unlike diamond, cubic boron nitride does not exist in a natural form and can only be formed synthetically. $\mathrm{PcBN}$ composites are produced via sintering of $\mathrm{cBN}$ powders in a high pressure $(7 \mathrm{GPa})$ and high temperature (1200-1400 K) environment with various ceramic binders (TiC, TiN, Al, $\mathrm{WC}-\mathrm{Co}, \mathrm{Ti}, \mathrm{TiN}-\mathrm{Al}$ ). The resulting material is thermally stable and extremely hard (Vickers hardness $500 \mathrm{~kg} \mathrm{~mm}^{-2}$ ) [1]. The properties that various grades of PcBN exhibit are dependent both on the cBN content (45\%-99\%) and the binder composition (ceramic or metallic).

Lower $\mathrm{cBN}$ content materials reveal better chemical wear resistance when turning continuous hardened steel bars with a minimum hardness of $56 \mathrm{HRC}$. Higher cBN content materials tend to be used in applications where abrasion resistance is nnecessary, thus these are predominantly utilised in industry for roughing and finishing of brake discs and cast-iron engine blocks [2].

Generally, tool wear mechanisms can be classified into four groups: abrasion, adhesion, fatigue dissolution/diffusion and tribo-chemical processes. However, tool wear may involve more than one wear mechanism and as such it is difficult to predict the dominant one. Focusing on the edge of a cutting tool, there are numerous factors that affect wear, for example high stress, high temperatures and chemical reactions between workpiece and tool; however these factors depend on a combination of tool geometry, cutting tool and workpiece material's composition and the corresponding thermo-mechanical and chemical phenomena occurring during machining. Research conducted to investigate the dominant wear patterns for PcBN cutting tools often provides contradictory findings for which mechanism is most common. Huang et al [3] reported that the observed wear patterns depend on the type of $\mathrm{PcBN}$ tools selected and they classified the main tool wear patterns into crater wear, flank wear, nose wear, notching, cracks, and microchipping. More et al [4] proposed flank wear as dominant wear mechanism in testing the machining performance of cBN-TiN coated carbide inserts versus PcBN inserts. They observed that flank wear for PcBN tools is less than that found on cBN-TiN coated tools which suggests lower cutting forces due to lower frictional forces and temperatures in the contact zone.

Recent research proposed functionalization of tool surfaces for improving wear resistance and to reduce adhesion of workpiece material to the cutting tool. For example, Xing et al [5] investigated the effects of surface texturing in various shapes and sizes to improve friction, anti-adhesive properties and wear behaviour in cemented carbide cutting tools. They discovered that microgrooves on the rake face of a cutting tool were effective in reducing cutting forces, which in turn improved the frictional behaviour at the chip-tool interface. They also found that the cutting forces increased proportionally to the groove width when this was in the range of $70-200 \mu \mathrm{m}$.

The defining characteristics of PcBN as cutting tool material can however hinder the tool fabrication process. Any material developments in PcBN tooling must reflect the symbiosis of: tool types, applications and workpiece materials that PcBN are required to work on and the importance of 'ease of tool fabrication' [6]. Manufacturing of periodical micro/nano surface textures on the tool rake face by laser, electrical discharge machining, micro grinding, mechanical machining, and chemical etching was reported [7], [8]. Among the available manufacturing techniques for micro texturing, short pulsed laser micro-machining enabled to generate precise microfeatures and alter the surface morphology of ultrahard cutting tool materials without showing significant surface damage [9], [10]. 
Sugihara and Enomoto [11] fabricated precise regular nano/micro grooves of depth 100-150 $\mathrm{nm}$ and track distance of $700 \mathrm{~nm}$ on the rake face of a cemented carbide cutting tool using a femto-second laser at a peak wavelength of $800 \mathrm{~nm}$. From scanning electron microscopy (SEM) and energy dispersive X-ray spectroscopy (EDX), they found that the nano/micro texture parallel to the main cutting edge improved anti-adhesion, but not satisfactorily on the cutting tool surface. Although it was confirmed that regular nano/micro grooves were not buried by adhesion at a cutting length of $1800 \mathrm{~m}$, a slight adhesion was observed; furthermore, they demonstrated that adhesion would worsen at increased length of cut possibly leading to tool breakage. Later they developed a cutting tool with banded nano/micro groove on the polished tool surface in a direction parallel to the main cutting edge in bands with $50 \mu \mathrm{m}$ width and 100-200 $\mathrm{nm}$ depth. They concluded that the newly proposed cutting tool improved anti-adhesive effects and lubricity of the cutting tool. Kawasegi et al [12] looked at the development of cutting tools with nanoscale and microscale surface textures to improve frictional behaviour, hence improving machinability. They identified friction present on the tool-chip interface as a dominant factor in determining the machinability of a material. They observed that controlling the levels of friction can limit the heat produced while cutting and control the plastic deformation of workpiece material. Hence, micro-texturing a cutting tool surface should improve its life-span because it improves fluid retention and reduces the contact between the tool and the chips [11]. One possible design identified was nano/micro-grooves concentrated around and, in the direction parallel to the main cutting edge. Upon evaluation of the anti-adhesion properties for this design, it was reported that the adhesion was reduced to less than half in comparison to the same tool having nano/micro-grooves overall [11]. Sugihara and Enomoto [13] later developed a cutting tool with micro stripe textured surface, namely grooves parallel to main cutting edge and grooves orthogonal to the main cutting edge to ensure anti-adhesive properties both in dry and wet cutting conditions. Their experimental results showed that the micro stripe textured surface improved the anti-adhesive properties and cutting performances in dry cutting. Deng et al [14] used laser machining for surface texturing on the rake face close to the main cutting edge of $\mathrm{WC} / \mathrm{Ti} / \mathrm{Co}$ carbide tools. They found that the nanoscale surface textures with/without $\mathrm{WS}_{2}$ solid lubricant coatings could significantly reduce the cutting forces, the cutting temperatures, and the tool-chip interface frictional coefficient. They also concluded that the rake face textured tools developed with $\mathrm{WS}_{2}$ coatings had the best cutting performance. Ma et al [15] numerically investigated the performance of microgroove textured cutting tools designed on the rake face of cemented carbide in dry $3 \mathrm{D}$ turning of titanium alloys. They summarized that manufacturing microgrooves with a width of $50 \mu \mathrm{m}$ on the rake face of a cutting tool was effective in reducing cutting forces, which improved the frictional behaviour at the chip-tool interface. The results showed that, at $50 \mu \mathrm{m}$ width, the cutting force components were less than those of the regular tool, but all forces became larger than those of the regular tool when the microgroove width increased further from 90 to $120 \mu \mathrm{m}$. Bio-inspired scale-like surface textures were proposed by Greiner and Schafer [16] with two variants: one with completely overlapping scales and another with scales arranged in separated rows. It was observed that in a lubricated condition, the surface textures significantly increased friction, that frictional forces were reduced by more than $40 \%$ under dry conditions and that the wide scale arrangement was performing superiorly to the completely overlapping grooves for both lubricated and non-lubricated conditions. Although much research has been conducted in the exploitation of laser technology as a manufacturing technique for micro and nano manufacturing of cutting tools, there is a lack in investigating and exploiting laser technology as a novel technique for surface chemical modifications aimed at functionalising the cutting tools' materials properties. The exploitation of the materials' microstructural characteristics and their allotropic changes post 
laser process has never been investigated to promote solid lubricant formation so to enhance the tool's service life.

In the need of reducing lubricant pollution to respond to environmental legislations, the objective of this paper is twofold: using a pulsed ytterbium-doped fibre laser $(1,064-\mathrm{nm}$ wavelength, $70 \mathrm{~W}$ maximum output power) cutting tools made of PcBN were textured to investigate and benchmark the effect of texturing angle on the machinability, anti-adhesive properties and chip formation mechanism. Secondly, the effect of laser texturing on solid lubricant formation was examined to enhance the anti-adhesive properties due to a controlled change of phase from the hard phase sp3 (c-BN) to the soft phase sp2 (h-BN).

\section{Materials and Methods}

\subsection{Workpiece material}

The material selected for precision turning tests was AISI 52100 with a chemical composition of $0.98-1.1 \%$ carbon, $0.15-0.3 \%$ silicon, $0.2-0.4 \%$ manganese, $1.3-1.6 \%$ chromium and less than $0.03 \%$ phosphorous and sulphur. The workpiece material, type $\mathrm{H} 05$ based on standard ISO 513:2004, was provided in bars with an initial diameter of $20 \mathrm{~mm}$ and a length of 500 $\mathrm{mm}$.

The material was thoroughly hardened to range $60 \pm 2 \mathrm{HRC}$. Test bars were treated as follows:

I. Carburising at $820^{\circ} \mathrm{C}-840^{\circ} \mathrm{C}$ for $26 \mathrm{~h}$

II. Quenching in water at $50^{\circ} \mathrm{C}$

III. Washing/Degreasing

IV. Tempering at $180^{\circ} \mathrm{C}$ for 2 hours

Characteristics data of hardness measurements was provided by the hardness treatment company which confirmed achieved hardness range to be $60 \pm 2$ HRC. Vickers hardness method was also used to validate the measurements provided by the manufacturer: seven points ranging from the outer edge and the inner edge were measured and a variance between $1-2 \%$ from the average hardness $(60 \mathrm{HRC})$ was recorded.

\subsection{Cutting tool material}

A WNGA080408 insert supplied by WNT was selected as cutting tool material (Figure 1). This is composed of a tungsten carbide (WC) blank characterised by a trigon (hexagon with three $80^{\circ}$ vertices) and six individual tips made of polycrystalline cubic boron nitride (PcBN) segments brazed on a WC blank. Based on the insert designation $(\mathrm{N})$, the insert relief angle was $0^{\circ}$. The inserts were selected to have a nose radius of $0.8 \mathrm{~mm}$ to allow testing of medium depths of cut (up to $0.3 \mathrm{~mm}$ ) and to avoid the introduction of heat as an additional process variable: small nose angles are weaker and have smaller cutting-edge engagement, making the tool more sensitive to the effects of heat. The inserts had a $30^{\circ}$ chamfer angle and a 0.2 $\mathrm{mm}$ chamfer land width (Figure $1 \mathrm{~b}$ ). The composition of the PcBN segments was $65 \%$ ultrahard phase of cubic boron nitride (average particle size, $3 \mu \mathrm{m}$ ) and a TiN binder making this grade suitable for precision turning of all common hardened steels in the range of application $\mathrm{H} 05-\mathrm{H} 10$ (ISO 513:2004).

Previous research [17], [18] suggested that negative rake angles are preferable in hard part turning due to the strength of the hardened steel. Therefore, a tool holder with a negative rake angle $\left(-8^{\circ}\right)$ was selected for its versatility and strength. The selected tool holder was a WNT MaxiLock-D DWLNR - 2525 M08 (right-handed) with a $95^{\circ}$ cutting tool edge angle. The clearance angle was $8^{\circ}$. 


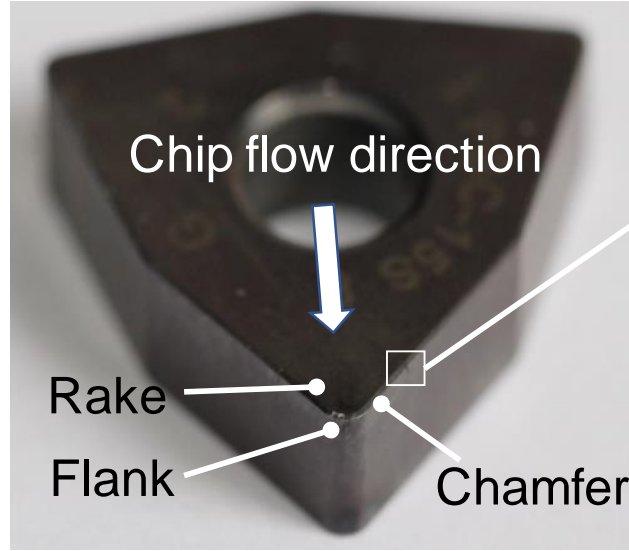

(a)

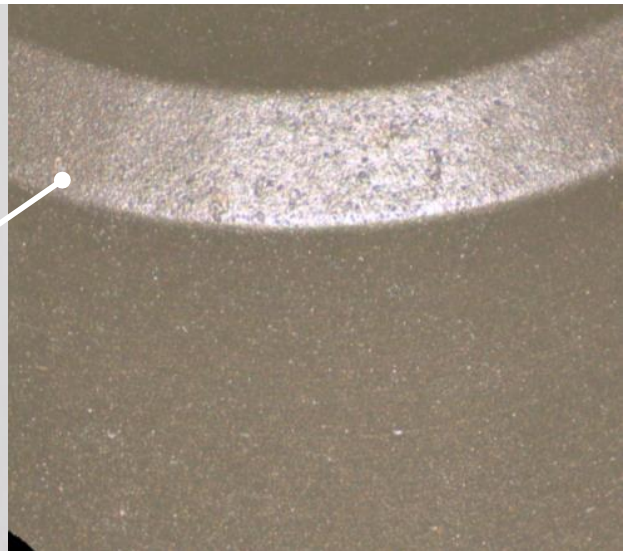

(b)

Figure 1: Representation of the cutting tool material used for testing (a) and detail of the chamfer (b).

\subsection{Laser micro-manufacturing}

An Innolas MMS single mode SPI fibre laser (1060 nm wavelength) with a $70 \mathrm{~W}$ maximum output power ' $P_{\max }$ ' was used to process the samples. The computer numerically controlled (CNC) laser machine was operated in pulse mode and delivered pulses based on direct modulation of the seed laser allowing programmed waveforms. At the waveform considered for the experiments the repetition rate for optimised peak power was $70 \mathrm{kHz}$, the pulse duration $46 \mathrm{~ns}$, and the maximum pulse energy $1 \mathrm{~mJ}$. Beam diameter ' $d_{i}$ ' at the focal point was measured to be approximately $29 \mu \mathrm{m}$. Generated laser fluence ' $\Psi$ ' was calculated using formula reported in equation 1 [19]. The investigation conducted prior manufacturing of the final micro-features is focused on developing a fundamental understanding of the complex thermo-mechanical phenomena occurring at various feed speeds, frequencies and intensities. These factors (feed speed ' $F S$ ', repetition frequency ' $f$ ' and laser intensity ' $I$ ') were selected at four levels (Table 1). The resulting experimental matrix is a Taguchi L12 orthogonal array. This set of 12 experiment was repeated twice to increase its robustness. This experimental design allowed to test a range of fluences between $10.6 \mathrm{~J} \mathrm{~cm}^{-2}$ and $63.6 \mathrm{~J} \mathrm{~cm}^{-2}$, calculated based on equation 1 .

$$
\Psi=\frac{4 \times I \times P_{\max }}{\pi \times d_{i}^{2} \times f}
$$

Table 1. Parameter values at each level.

\begin{tabular}{lccccc}
\hline \multicolumn{1}{c}{ Parameter } & Code & Level 1 & Level 2 & Level 3 & Level 4 \\
\hline Intensity $I(\%)$ & A & 10 & 15 & 20 & 30 \\
\hline Feed speed $F S\left(\mathrm{~mm} \mathrm{~s}^{-1}\right)$ & B & 500 & 1000 & 1500 & 2000 \\
\hline Frequency $f(\mathrm{kHz})$ & C & 50 & 70 & 100 & 140 \\
\hline
\end{tabular}

All test specimens were then placed in a methanol-filled glass vial and cleaned in a waterfilled ultrasonic bath for 30 minutes after laser processing to remove any debris or deposition due to the ablated particles. A Bruker NPFLEX was used for topographical analysis of the laser processed grooves based on ISO 4287. For each sample, three measurement of surface roughness parameters $(\mathrm{Ra})$ along the manufactured grooves (Figure $2 \mathrm{a}-\mathrm{b}$ ) and three measurement across the grooves were taken (Figure $2 \mathrm{c}-\mathrm{d}$ ). Results from the Taguchi L12 orthogonal array were analysed in Minitab to determine which factors had the biggest effect 
on ablation depth and surface roughness. The final parameters were selected based on this analysis. A JEOL Zeiss SEM was used to perform imaging and chemical composition using the mapping feature in the energy dispersive X-ray spectroscopy (EDX) technique to evaluate the extent of chemical changes and surface damage post-process.

(a)
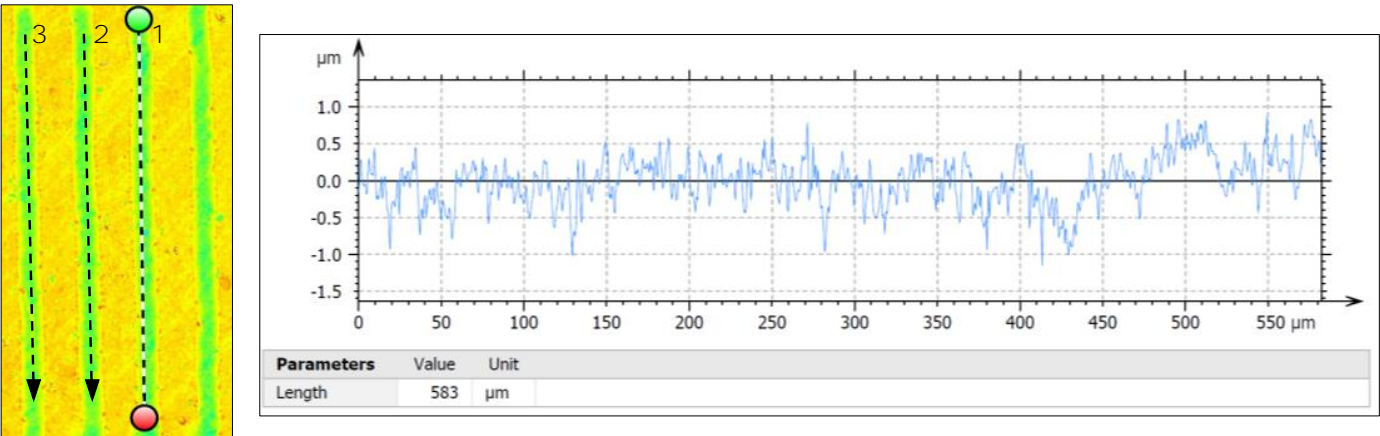

(b)

(c)
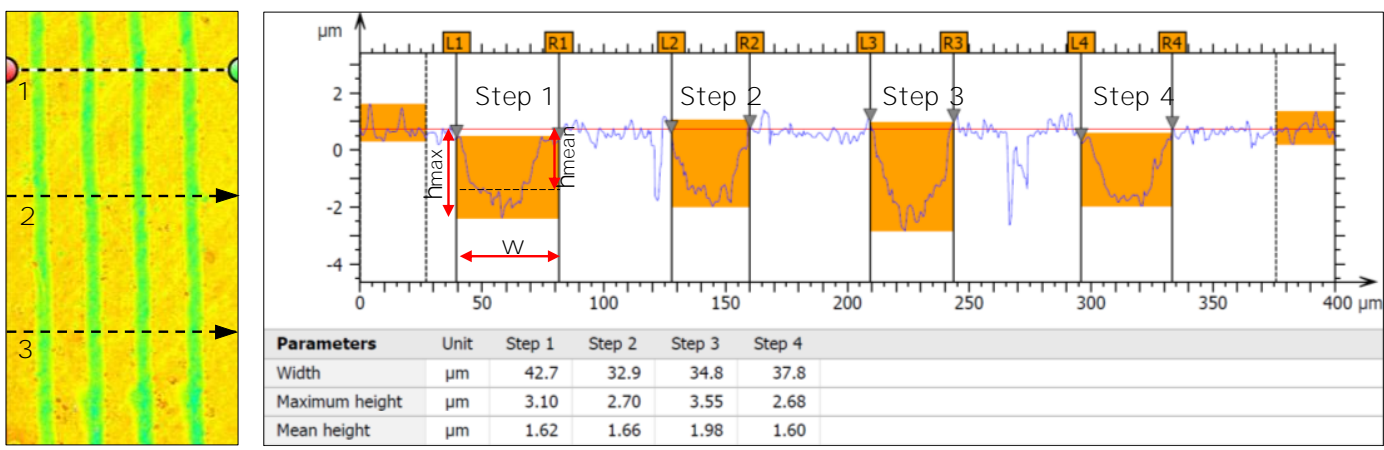

(d)

Figure 2: Example of measurement scan along (a) and across the manufactured grooves (c); example of results measurement from Bruker NPFLEX along (b) and across the manufactured grooves (d).

The rationale in selecting different designs was to reduce both frictional forces and heat generated during cutting, whereby reducing the overall surface contact with the workpiece and therefore improving cutting tool lifetime. Three different designs were investigated to evaluate the impact of grooves orientation in the tribology of metal cutting: Design 1 (Crosshatch) having pitch of $75 \mu \mathrm{m}$, an ideal ablation depth of $1-2 \mu \mathrm{m}$, and groove width of $30 \mu \mathrm{m}$ (Figure 3c). Design 2 with grooves perpendicular to chip flow direction (Figure 3b) and Design 3 with grooves parallel to chip flow direction (Figure $3 a$ ).

For the final laser micro manufacturing process, due to the shape of the cutting tool, a fixture was manufactured to guarantee the positioning of the tool in the jaws of the laser bed reliably and allow to locate the tool tip in relation to the laser head (Figure 4). A JOEL 2000FX TEM was used for the qualitative identification of allotropic changes occurring post laser process and to confirm the presence of solid lubricant in the textured tools. 
(a)

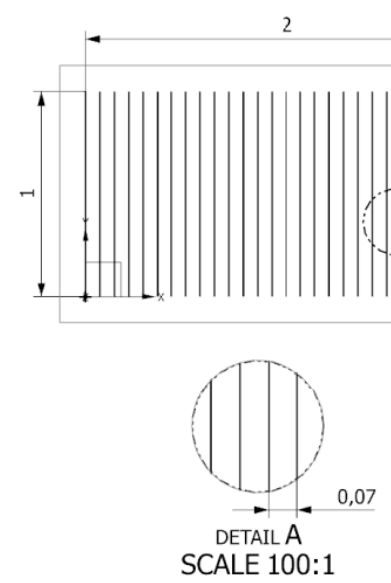

(b)
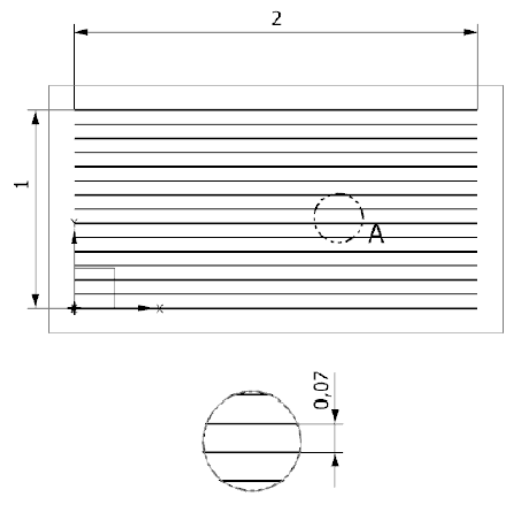

DETAIL A
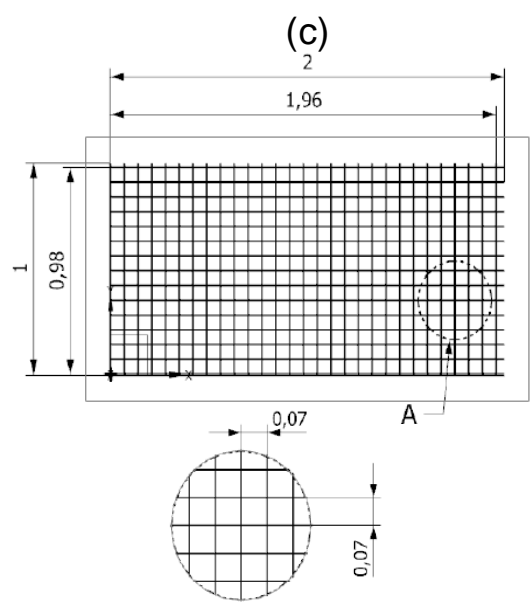

DETAIL A

Figure 3: Computer aided design of micro-geometries for laser machining: grooves parallel the chip flow direction (a), grooves perpendicular to chip flow direction (b), and crosshatch design (c).

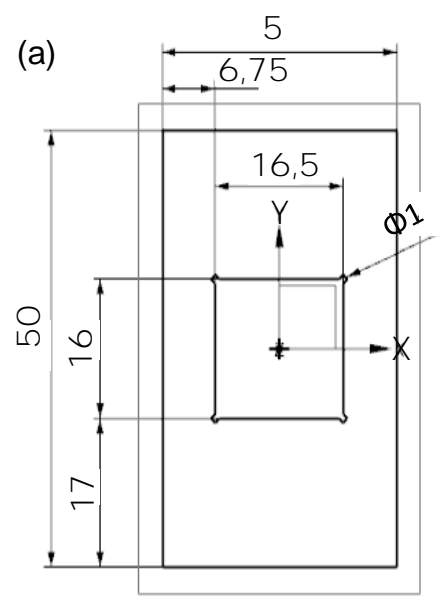

(c)

(b)
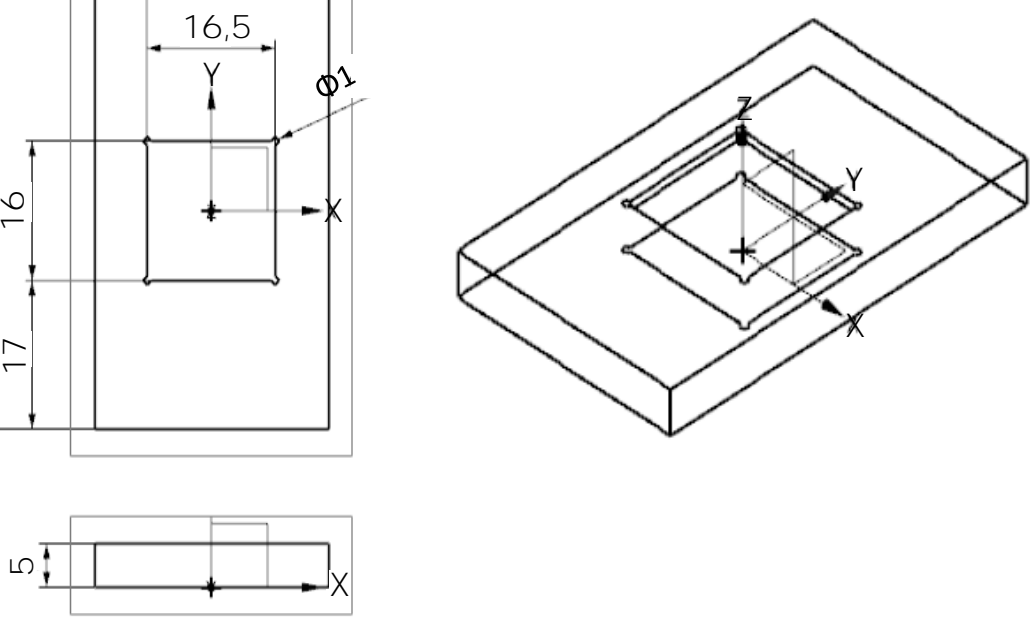

Figure 4: CAD design of the fixturing system: top view (a), cross sectional view (b) and 3D view (c).

\subsection{Turning tests}

A three-axis machining centre (Haas TL-1 CNC lathe; max. spindle speed 1,800 rpm; spindle power $30 \mathrm{~kW}$ ) was used for the turning tests; the cutting forces were acquired at a sampling rate of $10 \mathrm{kHz}$. A dedicated fixturing system was manufactured to accommodate a three-axis dynamometer (Kistler Kiag Swiss 9257A) connected to three (one for each axis) charge amplifiers (Kistler 5015) and then to a data acquisition board (Picoscope PC Oscilloscope) and dedicated Picoscope application to save and process the signals. A commercial tool holder (specified in Section 2.2) with rake angle of $-8^{\circ}$ was used to hold the inserts. Since the purpose of this study was to investigate the performance of grooved tools, the selection of optimal operating condition for the test was based on the standard hard part turning of lowmedium content PcBN tools based on More et al [4]. A depth of cut of $0.2 \mathrm{~mm}$, feed rate of $0.12 \mathrm{~mm} / \mathrm{rev}$, cutting speed of $100 \mathrm{~m} / \mathrm{min}$ and length of cut of $40 \mathrm{~mm}$ were used to perform the longitudinal cutting trials under dry conditions. For each cutting set, the turning process was stopped every 8 passes (correspondent circa to $150 \mathrm{~m}$ cutting length per pass) to monitor 
the wear progression mechanism via a combination of optical microscopy and white light interferometry.

\section{Results and Discussion}

\subsection{Effect of laser micro manufacturing on the topography and chemistry of cutting tool}

The effect of laser feed speed on surface roughness and topographical profile of the micrometric grooves was initially investigated. Increasing laser intensity resulted in deeper grooves with lower aspect ratio and roughness Ra of circa $200 \pm 2 \mathrm{~nm}$, compared to $160 \pm 20$ $\mathrm{nm}$ at $10 \%$ intensity (Figure 5a). Average surface roughness $\mathrm{Rz}$ of the as-received PcBN cutting tool based on 5 measurements was $230 \mathrm{~nm}$. Feed speed variation and repetition frequency showed to noticeably affect the achieved surface roughness Rz (Figure 5b): higher feed rates (above $1000 \mathrm{mms}^{-1}$ ) and low repetition frequency (below $90 \mathrm{kHz}$ ) should be favoured when low roughness (circa $1 \mu \mathrm{m}$ ) on the rake face are required by the specific application's requirements. Optimisation of the necessary laser intensity to achieve features depth in the order of 1-2 $\mu \mathrm{m}$ was carried out for the considered material and microgrooves with different aspect ratios were manufactured (Figure 5c-h) following the implementation of the Taguchi L12 orthogonal array reported in Table 1.
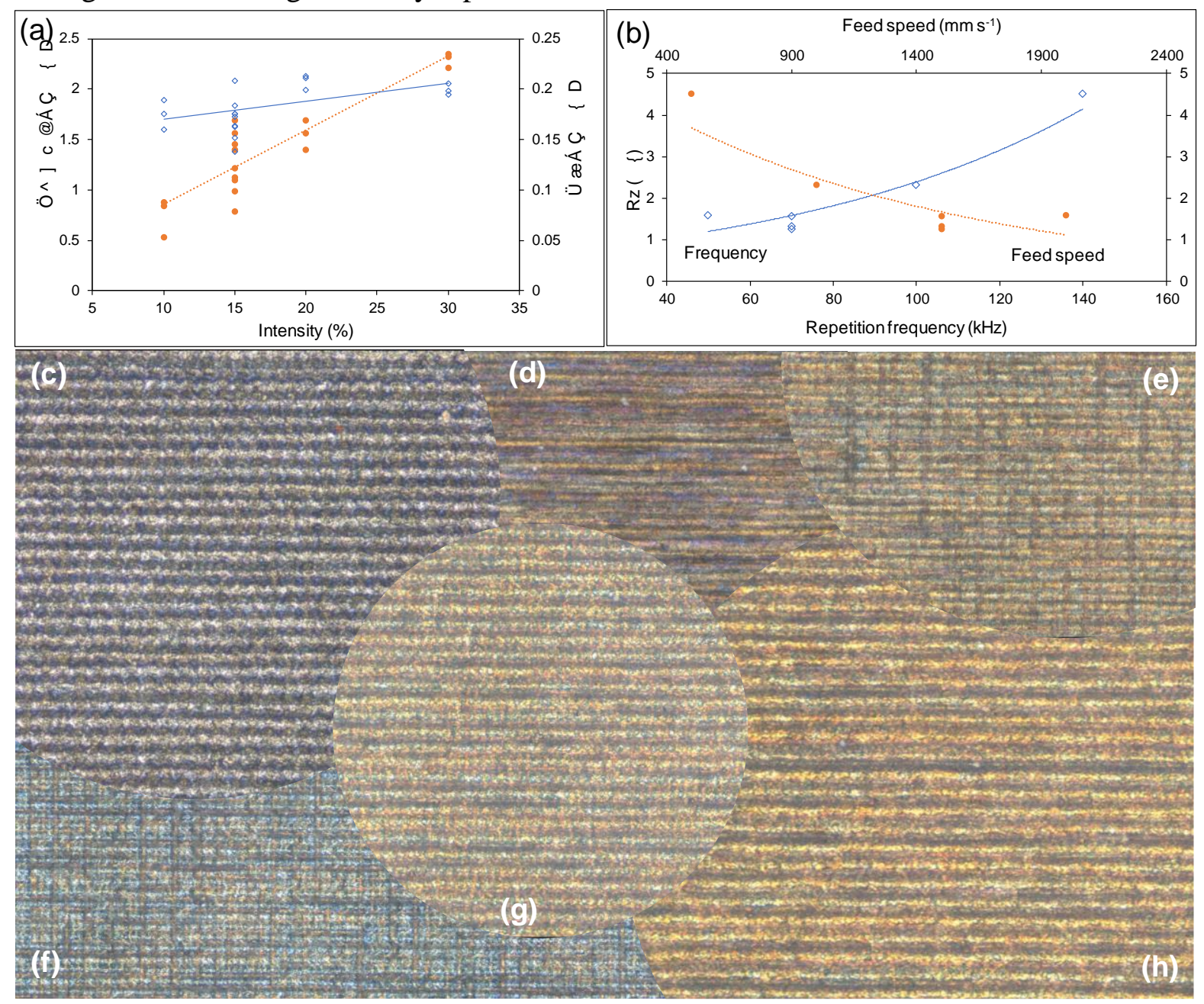

Figure 5: Relationship between laser intensity, depth of grooves and surface roughness Ra for PcBN materials (a); relationship between feed speed, repetition frequency and surface roughness Rz (b). 
Optical microscopy images at: $F S=1000 \mathrm{~mm} \mathrm{~s}^{-1}, \tau=27 \mathrm{~ns}, f=50 \mathrm{kHz}(\mathrm{c}) ; F S=400 \mathrm{~mm} \mathrm{~s}^{-1}, \tau=40$ $n s, f=140 \mathrm{kHz}(\mathrm{d}) ; F S=500 \mathrm{~mm} \mathrm{~s}^{-1}, \tau=19 \mathrm{~ns}, f=100 \mathrm{kHz}(\mathrm{e}) ; F S=500 \mathrm{~mm} \mathrm{~s}^{-1}, \tau=46 \mathrm{~ns}, f=35$ $\mathrm{kHz}$, ablated 5 times (f); $F S=500 \mathrm{~mm} \mathrm{~s}^{-1}, \tau=46 \mathrm{~ns}, f=35 \mathrm{kHz}$, ablated 1 time (g), FS = $500 \mathrm{~mm} \mathrm{~s}^{-1}$,

$$
\tau=27 \mathrm{~ns}, f=50 \mathrm{kHz}(\mathrm{h}) \text {. }
$$

To identify the laser ablation threshold of a $65 \% \mathrm{cBN}$ material, changes in surface chemical composition as a function of energy density and temperature were investigated, especially due to the relation between temperature and flow stress for PcBN materials. Previous research reported that for $\mathrm{PcBN}$ material with $65 \% \mathrm{cBN}$ content the flow stress is around $4 \mathrm{GPa}$ at $800^{\circ} \mathrm{C}$, while this drops to $2.5-3.5 \mathrm{GPa}$ for temperatures in the range $1000^{\circ} \mathrm{C}$ $1300^{\circ} \mathrm{C}$ [20]. Furthermore, the addition of binder phase (TiN) would also decrease the direct bonding between $\mathrm{cBN}$ grains and therefore reduce the flow stress. At the processing conditions proposed in this paper, the increased temperature might have favoured a reduction in flow stress. In fact, at $800{ }^{\circ} \mathrm{C}$ in a normal atmosphere TiN would oxidize resulting in reduced levels of titanium (60-85\% versus $75-93 \%$ for as-received) and increased levels of oxygen (10-90\% versus 3-15\% for as-received) as validated by EDX analysis of as-received and processed samples (Figure 6a-b).
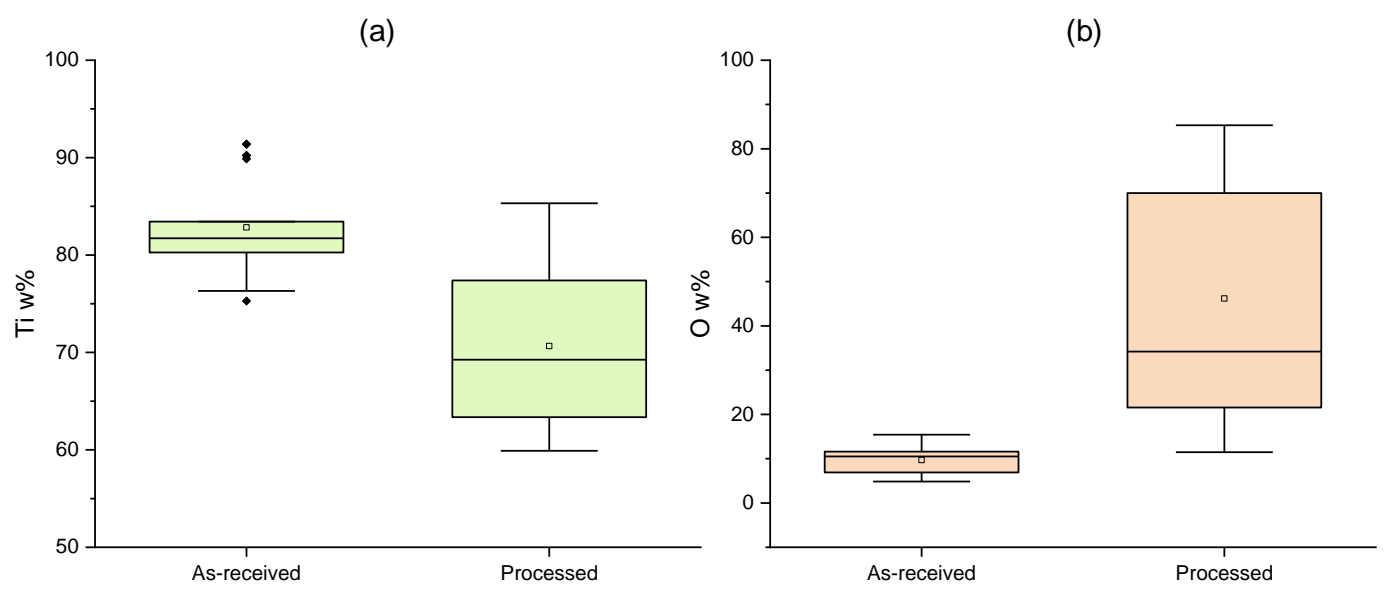

Figure 6: Chemical composition of as-received and processed samples for titanium (a) and oxygen (b).

Higher laser fluence $\left(\Psi>42.39 \mathrm{Jcm}^{-2}\right.$ ) resulted in micro cracks evident in the subsurface ablated area causing intergranular cracking (Figure $7 \mathrm{~b}$ ). The reduction of binder phase occurring while laser processing above $42.39 \mathrm{Jcm}^{-2}$ leaves the material prone to straininduced cracking due to dislocations pile-up caused by a large number of dislocations. This can be explained considering the physical principle of volumetric strain produced in a material due to the change in temperature which has been applied to previous research to explain the wear behaviour of polycrystalline diamond at elevated temperatures. The mismatch of thermal expansion coefficients $\left(1.210^{-6} \mathrm{~K}^{-1}\right.$ for $\mathrm{cBN}$ and $9.310^{-6} \mathrm{~K}^{-1}$ for TiN) would induce compressive stresses in the $\mathrm{cBN}$ grains and low tensile stress in the TiN binder, causing intergranular residual stresses between the $65 \% \mathrm{cBN}$ grains ( $3 \mu \mathrm{m}$ grain size) and the TiN binder. 


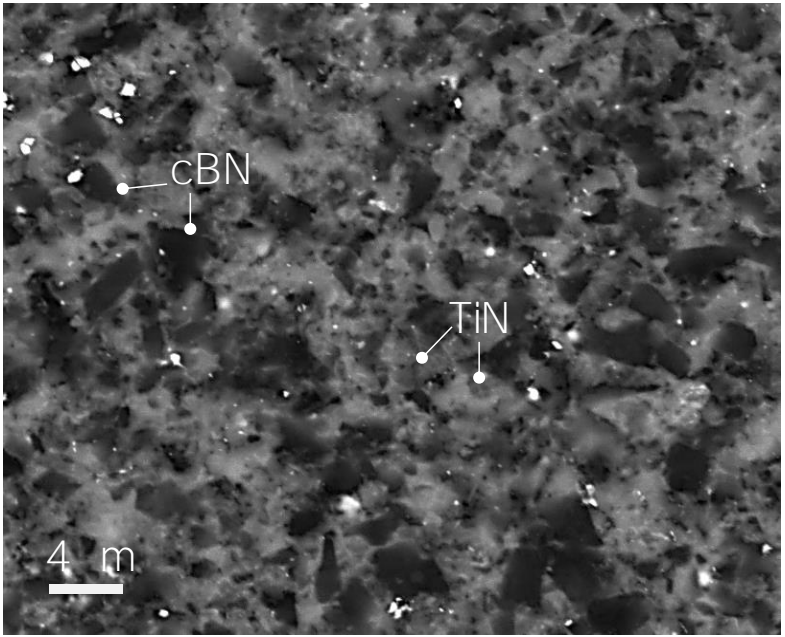

(a)

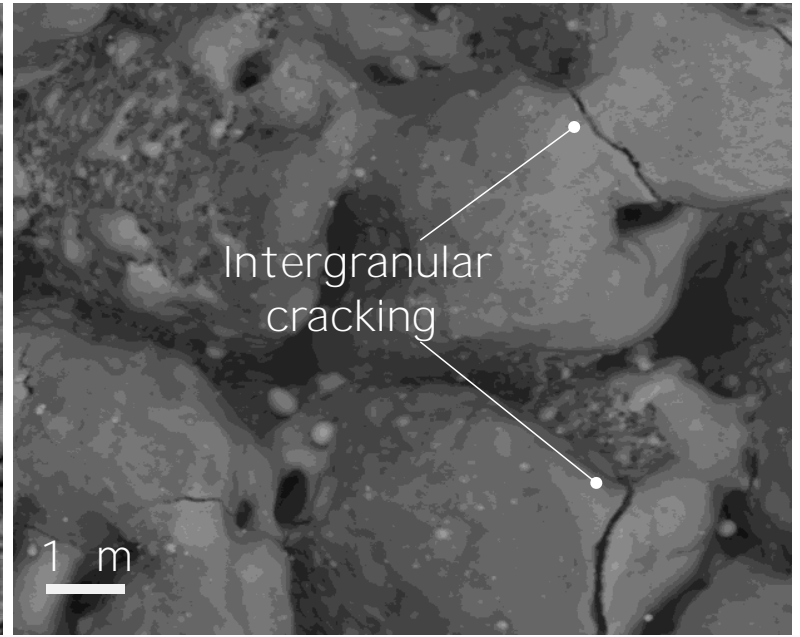

(b)

Figure 7: SEM images of PcBN $(65 \% \mathrm{cBN})$ for the as-received cutting tool material (a) and laser processed at fluence above $42.39 \mathrm{Jcm}^{-2}(\mathrm{~b})$.

PcBN material at low-energy $\left(\Psi<22.7 \mathrm{Jcm}^{-2}\right)$ was the adopted threshold for the proposed manufacturing process to achieve repeatable micro-scale grooves (Figure 8). The final laser parameters selected to micro-machine the PcBN cutting tips were feed speed $(F S)$ of $500 \mathrm{~mm}$ $\mathrm{s}^{-1}$, intensity $(I)$ of $15 \%$, fluence $(\Psi) 22.7 \mathrm{Jcm}^{-2}$ and frequency $(f)$ of $70 \mathrm{kHz}$. The grooves were $1.5 \pm 0.2 \mu \mathrm{m}$ in depth, $30 \mu \mathrm{m}$ in width and spaced at a pitch (centre to centre) of 70-75 $\mu \mathrm{m}$ depending on design as depicted in Figure 8. Three different texture designs on the surface of the tool namely grooves perpendicular to the chip flow direction (CFD), grooves parallel to $\mathrm{CFD}$, and a crosshatch design were manufactured and their performance in application was benchmarked to a non-textured tip made of the same material (PcBN) and cutting-edge geometry (WNGA080408).

(a)

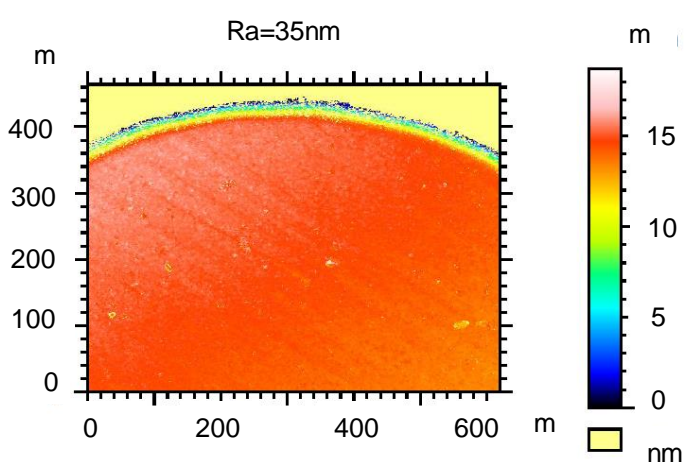

(c)

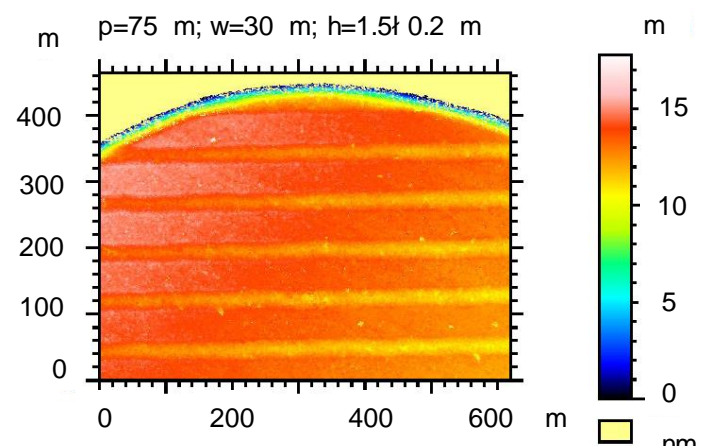

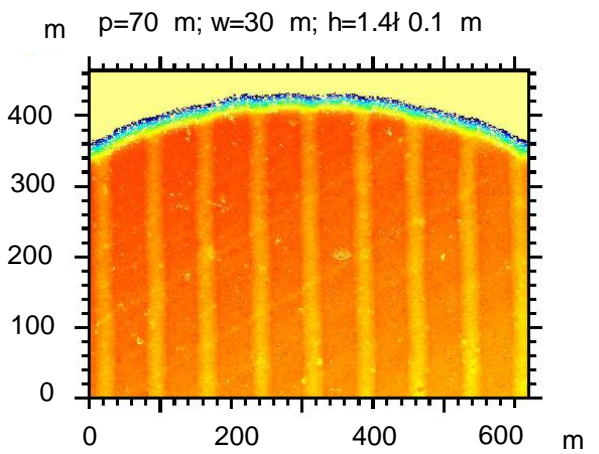
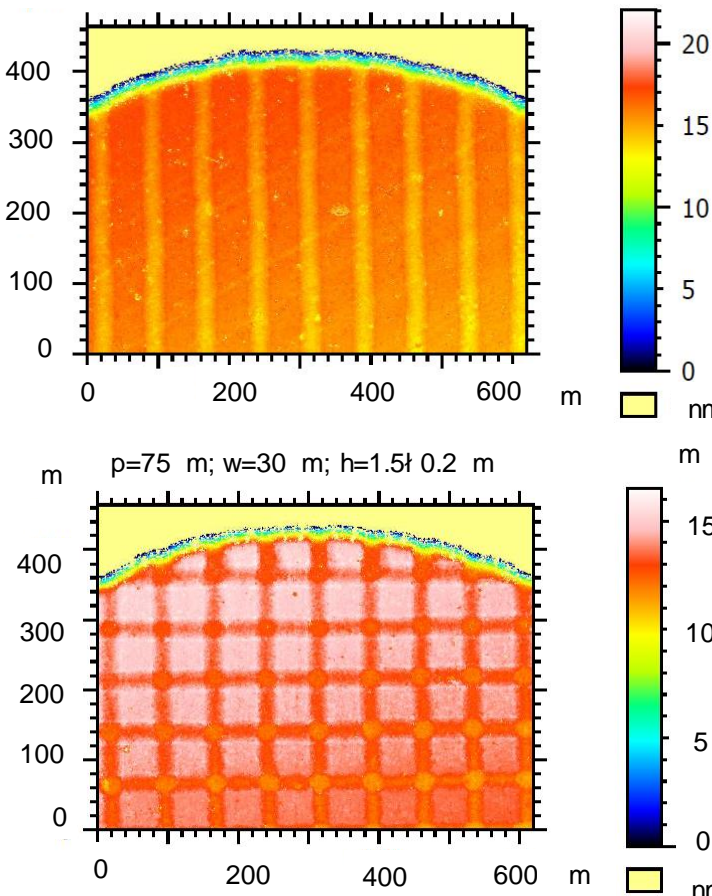

$\varepsilon m(d)$

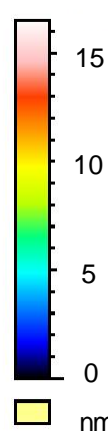


Figure 8: 3D interferometry scans of: as-received benchmark tip (a), tool with micro-grooves parallel to chip flow direction (b), tool with micro-grooves perpendicular to chip flow direction (c); tip with crosshatch micro-grooves (d).

\subsection{Performance of laser micro manufactured cutting edges in turning}

A tool life criterion of maximum flank wear $\mathrm{Vb}$ max of $0.15 \mathrm{~mm}$ was applied in this study and this was reached only for the benchmark cutting tool, while the cross hatch and perpendicular groove design showed their superiority in decreased tool wear (Figure 9a) and reduced cutting forces (Figure 13).

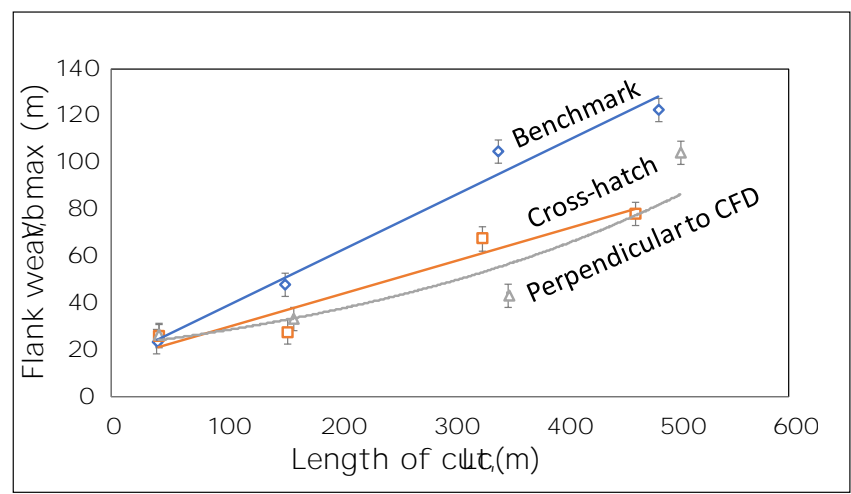

(a)

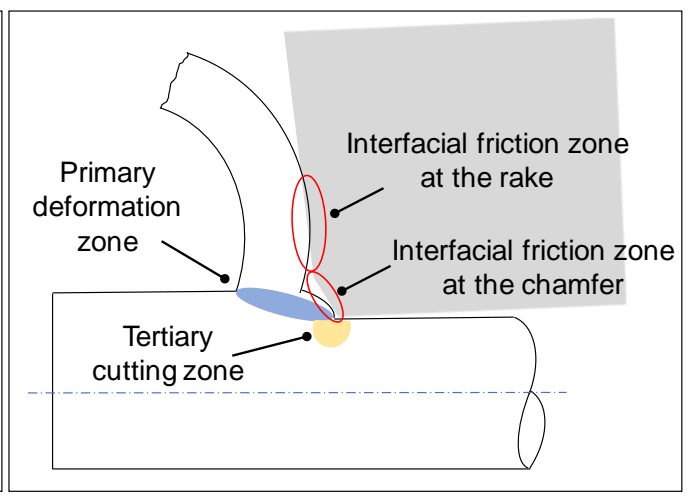

(b)

Figure 9: A comparison of flank wear ( $\mathrm{Vb}$ max) progression at increasing lengths of cut (a). Schematic of the plastic deformation in the cutting zone (b).

From the initial wear screening test, it was noticed that grooves parallel to CFD decreased wear performance, therefore the turning trials were not carried on for this design. Therefore, from this point onward, the nomenclature 'lasered tools' refers only to grooves perpendicular to CFD and crosshatch design.

All the tools processed via laser showed better wear resistance at the flank face, which strongly affects the finished surface in any machining operation. The laser process might have caused a dispersion strengthening mechanism in which the titanium compound used as binder reacted with boron leading to formation of $\mathrm{TiB}_{2}$, which is reported to have a Vickers hardness of 34GPa [22] and therefore responsible for the improvement of wear resistance. The expected wear mechanism for a $65 \% \mathrm{cBN}$ cutting tool material in precision turning of hardened steel is a combination of crater (Figure 10d) and flank wear with notch wear showing at the trailing edge when the quality of the edge is compromised (Figure 10e). The thermal and CNC processing path strategies adopted during the manufacturing process seem to have strongly affected the extent of crater and flank wear. A shift from purely crater wear to chipping concentrated on chamfer edge was revealed for the design with grooves perpendicular to CFD (Figure 10e). A wider but shallower crater wear was highlighted for the crosshatch design, accompanied by localised chipping on the flank face possibly due to local stress concentration, while negligible flank wear was identifiable at a length of cut of $500 \mathrm{~m}$ (Figure 10i). The measurement of the width and height of the chipping for the crosshatch design revealed an area of approximately $150 \mu \mathrm{m}$ by $80 \mu \mathrm{m}$ (Figure 10f). The chipping is likely triggered by the reduction of surface area between the workpiece and the chamfer caused by the textures, as depicted in the white areas in Figure 10 for the crosshatch design. The shift of wear mode from a combination of flank and crater to a mechanism dominated by chipping is comparable to turning of semi-interrupted components typical of H10-H15 applications based on ISO 513:2004. Although tools with grooves perpendicular to chip flow direction caused less grooves to be in contact with the workpiece for a specific contact length 
(Figure 11), the workpiece encounters at any time full-length deep valleys/flat surfaces whereas in the cross hatch design it repetitively encounters deep valleys/flat surfaces at regular intervals of contact lengths. This is validated by the investigation on the relationship between geometrical design and flank wear progression which revealed that grooves perpendicular to CFD followed an exponential relationship between length of cut and wear extent, while crosshatch design and benchmark were represented by a linear relationship. The work done by the cutting tool in the machining of hardened steel is dissipated mainly in plastic deformation (i.e. work done in shear deformation) and in friction (i.e. work done to overcome tool/chip interfacial friction) [23]. Therefore, to fully understand the underlying mechanism responsible for changes in wear mechanism, the tribology of the cutting process and the different shear zones should be considered for the specific insert geometry selected for the trials. The area in which friction is the predominant deformation mechanism is the secondary shear zone represented by the interfacial friction zone in Figure $9 \mathrm{~b}$. For the insert geometry selected in this paper, the standard interfacial zone/secondary deformation zone has been rearranged to show the effect of having a chamfer geometry with a $30^{\circ}$ chamfer angle. Although the expected rake angle due to tool holder geometry is $-8^{\circ}$, before the chip encounters this angle, the effective rake angle at the first contact zone with the workpiece/chip is the chamfer angle itself. Therefore, part of the chip forms in the interfacial friction zone at the chamfer and might remain trapped. Here chips undergo high stress and strain, causing increased temperature and wear rate. Although the width of the lengths was expected to be the same due to the constant depth of cut used for all the experiments, in the case of the tools textured by laser the contact length is smaller: $400 \mu \mathrm{m}$ and $150 \mu \mathrm{m}$ for perpendicular to CFD and crosshatch design respectively and circa $500 \mu \mathrm{m}$ for benchmark tool (Figure 10g-i).

The change in wear mechanism and the reduction in crater wear can be explained considering the geometry of the textures and its implications in the primary and secondary deformation zones as well as the chemical transformations induced by the laser processing. It is expected that grooves parallel to the chip flow direction would promote chip escape through the grooves due to reduced tool-chip contact area, resulting in decreased temperature, faster chip flow and reduced plugging of the textures, therefore limiting the micro-grooves to act as a micro-trap for wear debris [24]. However, an opposite phenomenon would occur when grooves are perpendicular to the chip flow direction: an increase in temperature would trap the chip in the chamfer area. This phenomenon would explain the wear mechanism identified for the design with grooves perpendicular to CFD where chipping concentrated on chamfer radius was identified (Figure 10e). The increase in temperature would make the chip flow slower trapping some of it in the chamfer thereby causing a considerable wear concentrated at the chamfer edge. The effect of number of features in contact with the forming chip for different contact lengths (Figure 11) would also explain the formation of wear at the edge for grooves perpendicular to CFD (Figure 10w). It is in fact probable that in the first area of contact, the workpiece might have encountered a groove; this would have contributed to decrease the effective chamfer angle.

Some degree of workpiece adhesion was highlighted for the tool with grooves perpendicular to CFD (Figure 10b) and crosshatch design (Figure 10c) although it was less pronounced for the latter. This result is in accordance with observation of a slight adhesion on carbide tools with nano/micro grooves of depth 100-150 nm [11] and it is mostly attributable to the geometrical effect in the secondary deformation zone (interfacial zones in Figure 9b). For the chamfer and grooves geometries selected for the tests, the chip formation mechanism was affected by the direct encounter at the first contact zone with the workpiece/chip. In this investigations the chamfer edge was manufactured with a grove in its highest depth (Figure $10 \mathrm{e})$, therefore the actual encountering angle between the workpiece and the chip was even 
higher than the chamfer angle. In this case three interfacial secondary deformation areas were formed: one due to the groove itself, one due to localised stresses and temperatures caused by the repetitive encounter between flat surfaces (white areas in Figure 11) and deep valleys (black areas in Figure 11) and the forming chip; and the third one due the grooves and the effective tool rake angle. High cutting stresses and high temperatures subsequently promoted shear induced flow of workpiece material in the cutting zone leading to the formation and flow of the cutting chips from the hardened steel (Figure 10b).

Pitting of the rake face of the tool was more pronounced in the benchmark tool than in any of the textured tools (Figure 10b-c).

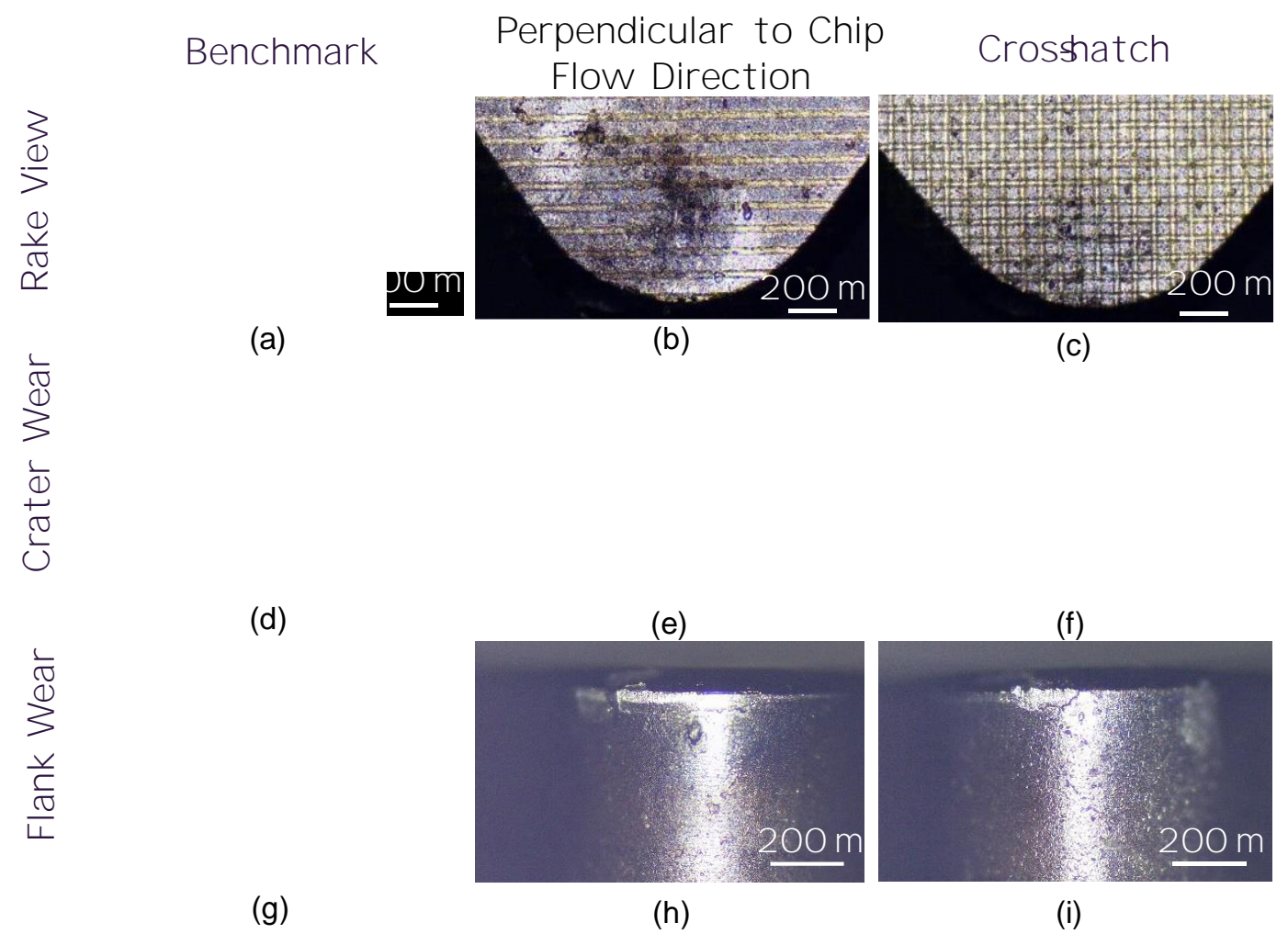

Figure 10: Rake view, crater wear and flank wear (length of cut, $\mathrm{Lc}=500 \mathrm{~m})$ of benchmark tool $(\mathrm{a}, \mathrm{d}$, $\mathrm{g}$ ), cutter with grooves perpendicular to chip flow direction $(\mathrm{b}, \mathrm{e}, \mathrm{h})$ and tool with crosshatch design $(\mathrm{c}, \mathrm{f}, \mathrm{i})$. 


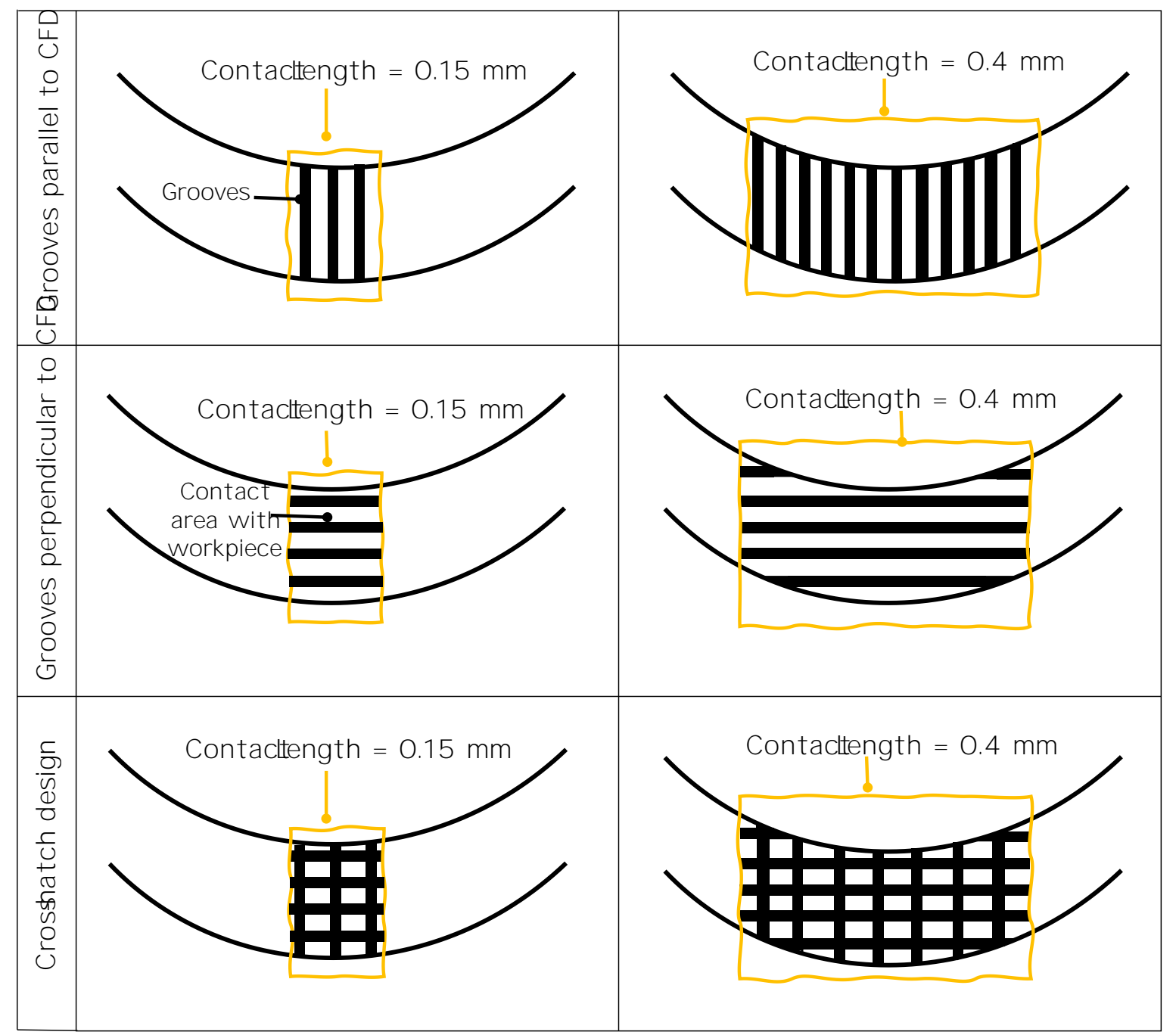

Figure 11: Schematic of features on the chamfer edge as a function of design and contact length with the workpiece.

In regard to the chemical transformations induced by the laser processing on PcBN materials, previous experimental findings from the characterisation of the subsurface integrity of laser ablated polycrystalline boron nitrides via high resolution transmission electron microscopy (HRTEM) revealed small transitionary bands formed after the ablation process and an undisturbed composite substructure below the hexagonal boundary. The bands were sites of amorphous boron nitride $(\alpha-\mathrm{BN})$ and hexagonal boron nitride (h-BN) formed after the ablation process, whereby proving a relation between laser energy distribution and extent of material allotropic phase change for PcBN materials [25]. In this context, the micro grooves manufactured in the lasered tools (maximum depth, $2 \mu \mathrm{m}$ ) might have had two actions. Firstly, they would work as micro reservoirs for the hexagonal boron nitride formed as a result of the laser process, as revealed by the h-BN bands with d spacing in the range $2.5-3 \AA$ in the TEM results (Figure 12c). The spacing of groups of the visible crystallographic lattice planes was determined using Digital Micrograph software and the direct comparison of the atomic distance of $\mathrm{h}-\mathrm{BN}$ in the 002-lattice direction indicated the likely presence of this allotropic phase.

Secondly, the hexagonal boron nitride trapped in the deepest area of the grooves [21] would also act as a solid lubricant. When cutting hardened steels, due to its higher yielding stress, the frictional stress acting on the rake face of the cutting tool is noticeably increased. Due to frictional forces, the solid lubricant (h-BN) which formed on the surface of the tool due to the 
laser processing acted as a lubricant coating just for a short time, enough to reduce initial adhesion between tool and workpiece and reduce wear by improving heat dissipation rate. This was revealed for both lasered designs, however the CAD/CAM machining path strategy adopted for the manufacture of the crosshatch design affected the energy density on the substrate allowing to increase the extent of solid lubricant formed as a result of the laser machining when compared to the tool with grooves perpendicular to CFD. The increased solid lubricant would avoid reaching thermal decomposition temperature at the toolworkpiece interface. This would also explain why the flank wear boundary for the crosshatch design was found to be fuzzy and the lowest flank wear was measured.

(a)
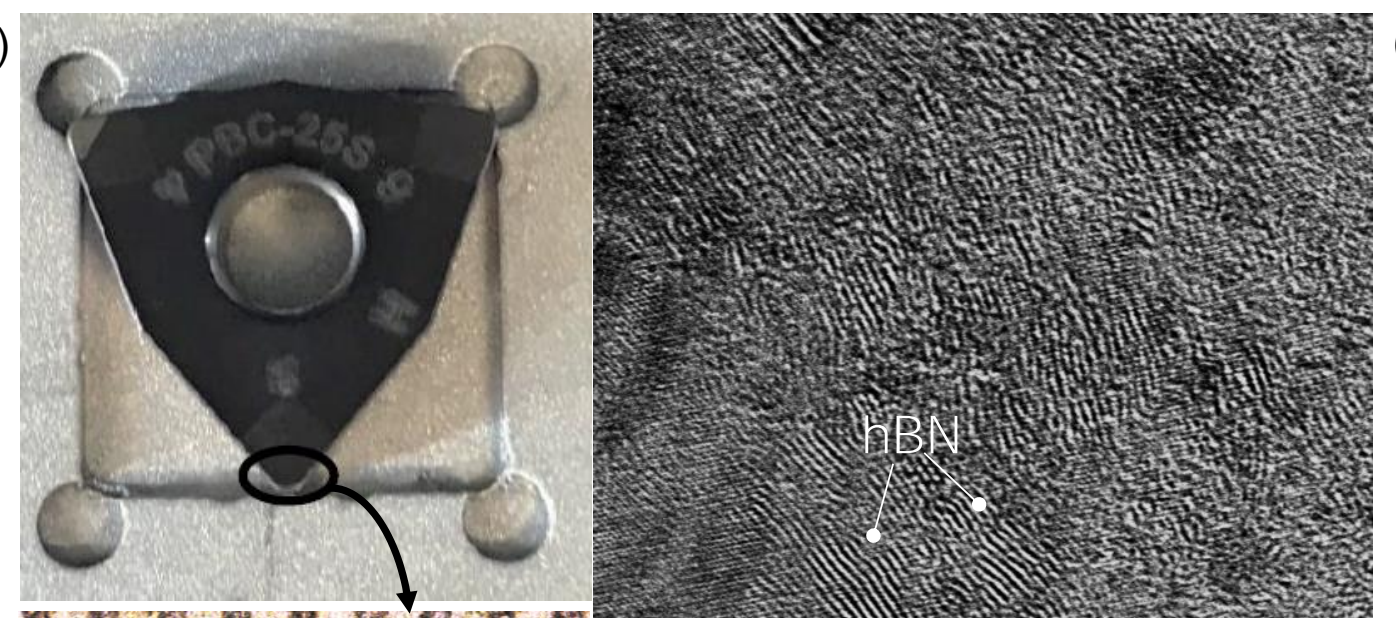

(c)

(b)
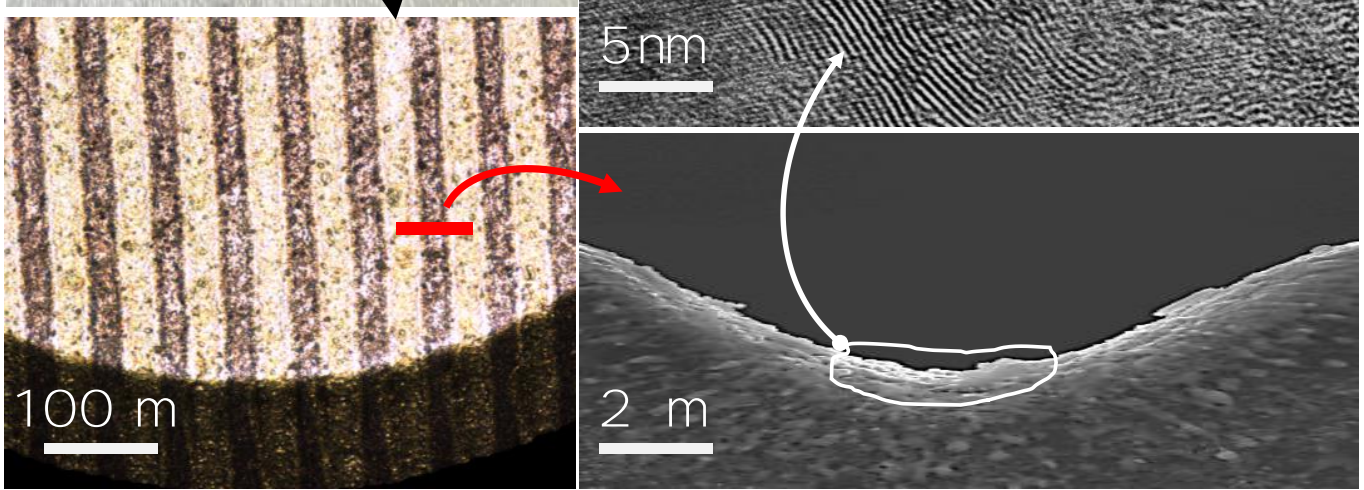

(d)

Figure 12: Cutting tool tip before laser machining (a); optical microscopy image of the detail of micro grooves on the rake face of the tip (b); transmission electron microscopy (TEM) image of the groove (c); scanning electron microscopy (SEM) image of the cross section of the grooves (d).

Results from the on-line condition monitoring of the cutting forces revealed a clear reduction of cutting and feed forces for the tested laser textured tools (Figure 13). The percentage reduction in the mean force components between textured and untextured tools was measured to be $20 \%$ for cutting force and $30 \%$ for feed force when benchmarked to the commercially available cutting tool. This was triggered by two contributing factors: the effect of grooves geometries and their impact on the effective contact angles between tool and workpiece; and the effect of solid lubrication caused by the laser-induced allotropic conversion. Lubrication is known to act in the secondary and tertiary deformation areas, however standard liquid lubricant cannot be sustained along these interfaces in high-speed machining. Direct comparison of the atomic distance of the h-BN bands with d spacing in the range $2.5-3 \AA$ (as shown by TEM) confirmed that the solid lubricant formation in the crosshatch micro grooves reduced friction and temperatures resulting in lower average cutting and feed forces. 
The decrease cutting forces for the textured tools was also attributable to the difference in the contact length between the tool and work material which was measured to be $400 \mu \mathrm{m}$ and $150 \mu \mathrm{m}$ for grooves perpendicular to CFD and crosshatch design respectively and circa $500 \mu \mathrm{m}$ for benchmark tool. Calculations of the number of grooves in contact with the workpiece in the chamfer area (Figure 11) allowed to provide an estimate of actual features encountering the workpiece at any time: full-length deep valleys/flat surfaces were faced by the forming chip in the tool with grooves perpendicular to CFD, while interrupted encounters of deep valleys/flat surfaces were met by the chip in the crosshatch insert. This result is in accordance with the measured feed force scatter data represented in Figure $13 \mathrm{~b}$. The encountered interruption deep valley/flat surface in the crosshatch design caused higher fluctuations in feed force (orange scatter plot in Figure 13b) compared to the design with grooves perpendicular to CFD (grey scatter plot in Figure 13b) as depicted by the maximumminimum feed force ratio of $100 \mathrm{~N}-20 \mathrm{~N}$ in the first case and $85 \mathrm{~N}-65 \mathrm{~N}$ in the latter case. The results reported in this paper showed that laser micro texturing reduces cutting forces (Figure 13a), cutting temperatures, and tool-chip interface frictional coefficient and these are in accordance with data from literature for $\mathrm{WC} / \mathrm{Ti} / \mathrm{Co}$ carbide tools textured and tested in lubricated [14] and dry conditions [11], [12]. 


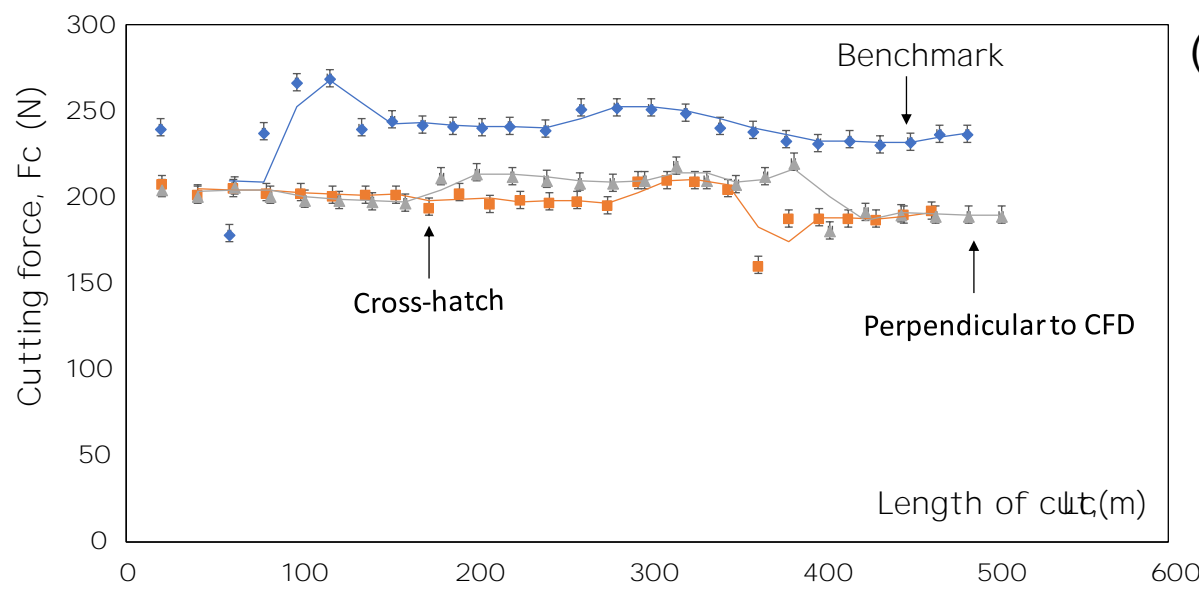

(a)
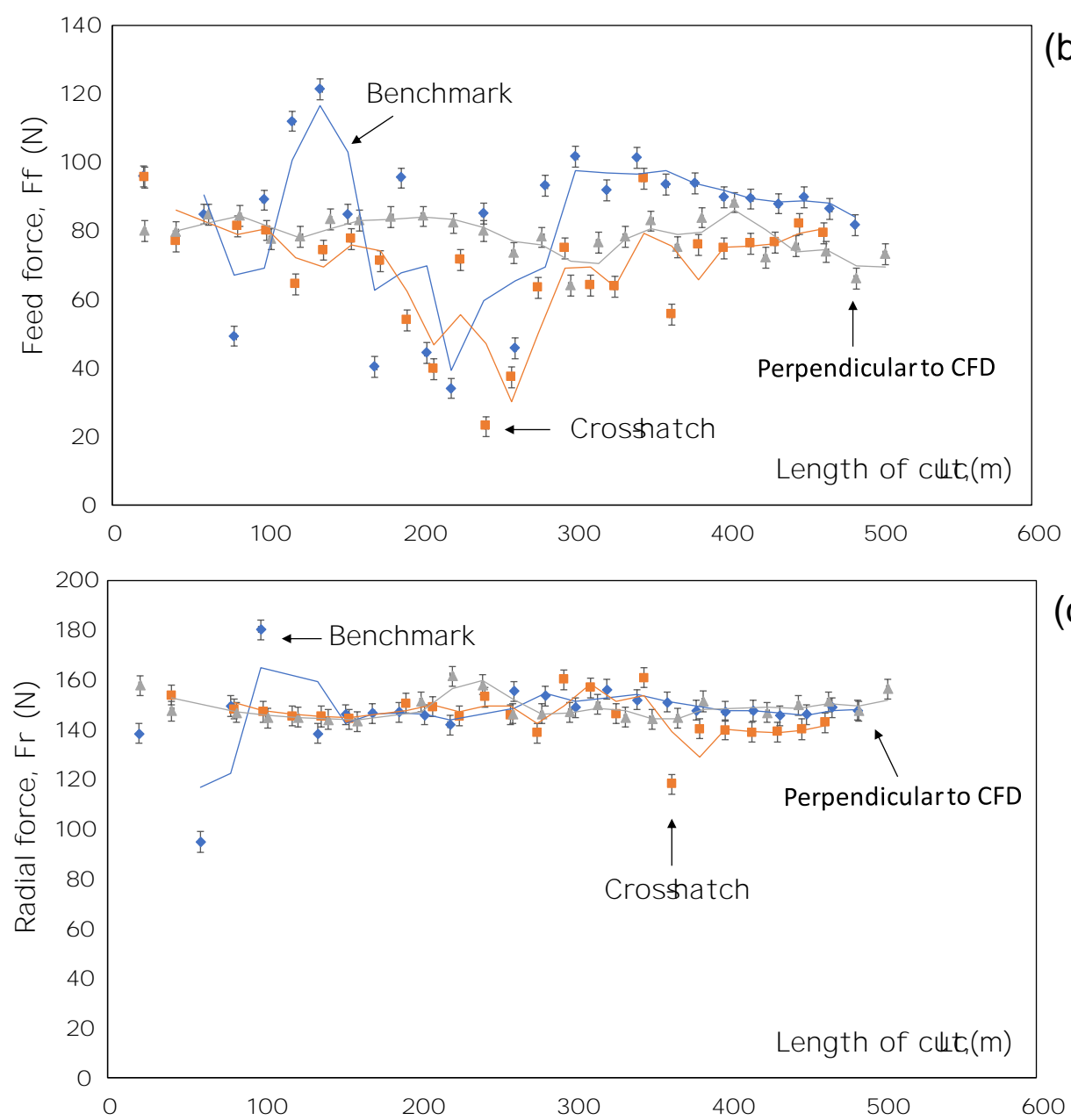

Figure 13: Condition monitoring during the cutting process of: cutting force for benchmark and lasered designs (a), feed force for benchmark and lasered designs (b), radial force for benchmark and lasered designs (c).

\section{Conclusions}

An optimised laser process enabled the manufacture of micrometric grooves on the rake face of a composite cutting tool to improve wear behaviour in the machining of hardened steels. 
The combination of white light interferometry with SEM allowed a quantitative analysis of the chemical transformations occurring on the cutting tool's subsurface when exposed to the laser. An energy density of $42.39 \mathrm{Jcm}^{-2}$ was identified as threshold above which intergranular cracking is generated on the subsurface ablated area. This is believed to be triggered by a reduction of binder phase which leaves the material prone to strain-induced cracking due to dislocations pile-up caused by a large number of dislocations. For textures depths in the order of $260 \mathrm{~nm}$ and post process roughness in the order of tens of nanometres, condition monitoring of machining forces allowed to identify a $20 \%$ reduction of cutting force and $30 \%$ reduction of feed force when benchmarked to the commercial cutting tools. Higher fluctuations were encountered in the crosshatch design caused by regularly interrupted deep valleys/flat surfaces which affected the number of actual features encountering the workpiece at any time.

A reduced crater and flank wear were achieved in dry turning for all the textured designs; in particular, a shift from purely crater wear to chipping concentrated on the chamfer radius was revealed in for the design with grooves perpendicular to CFD. A wider but shallower crater wear was highlighted for the crosshatch design, accompanied by localised chipping on the flank face possibly caused by localised stress. This was due to the number of features in contact with the forming chip for different contact lengths: in the first area of contact, the workpiece might have encountered a groove; this would have contributed to decrease the effective chamfer angle.

Due to the chamfer and grooves geometries selected for the tests in the grooves perpendicular to chip flow direction, the chamfer edge was manufactured with a groove in its highest depth therefore the actual encountering angle between the workpiece and the chip was even higher than the chamfer angle. This caused the formation of three interfacial secondary deformation areas: one due to the groove itself, one due to localised stresses and temperatures caused by the encountering of repetitive flat surfaces and deep valleys with the forming chip, and the third one due the grooves and the effective tool rake angle.

The combination of white light interferometry with SEM/TEM analysis allowed a qualitative analysis of the allotropic phase change present on the lasered designs before testing. Formation of h-BN was revealed in the micro grooves at a maximum depth of $2 \mu \mathrm{m}$ which would have acted as a solid lubricant for a short time, enough to reduce initial adhesion between tool and workpiece and reduce wear by improving heat dissipation rate and thereby reducing the forces in the direction of the primary and secondary deformation zones.

\section{Competing interest statement}

I declare that I have no significant competing financial, professional, or personal interests that might have influenced the performance or presentation of the work described in this manuscript.

\section{Authors' contribution statement}

M. Pacella devised the project, the main conceptual ideas and proof outline. M. Pacella encouraged D. Brigginshaw to investigate specific tool designs and supervised the findings of this work. D. Brigginshaw carried out the experiments on laser manufacturing, characterisation (3D white light interferometry and optical microscopy) and cutting tool testing under M. Pacella's supervision. M. Pacella carried out the tools' characterisation (scanning electron microscopy and transmission electron microscopy), wrote the manuscript, analysed and discussed the results. 


\section{References}

[1] Nassau K, Nassau J. The history and present status of synthetic diamond. J Cryst Growth 1979; 46(2):157172.

[2] Monteiro SN, Skury ALD, De Azevedo MG, Bobrovnitchii GS. Cubic boron nitride competing with diamond as a superhard engineering material - an overview. J Mater Res Technol 2013; 2(1):68-74.

[3] Huang Y, Chou YK, Liang SY. cBN tool wear in hard turning: a survey on research progresses. Int J Adv Manuf Technol 2006; 35(5-6):443-453.

[4] More AS, Jiang W, Brown WD, Malshe AP. Tool wear and machining performance of cBN-TiN coated carbide inserts and PcBN compact inserts in turning AISI 4340 hardened steel. J Mater Process Technol 2006; 180(1-3):253-262.

[5] Xing Y, Deng J, Wang X, Ehmann K, Cao J. Experimental assessment of laser textured cutting tools in dry cutting of aluminium alloys. J Manuf Sci Eng 2016; 138(7):0710061-07100610.

[6] Cook MW, Bossom PK. Trends and recent developments in the material manufacture and cutting tool application of polycrystalline diamond and polycrystalline cubic boron nitride. Int J Refract Met Hard Mater 2000; 18:147-152.

[7] $\mathrm{Hu}$ T, Hu L, Ding Q. Effective solution for the tribological problems of Ti-6Al-4V: combination of laser surface texturing and solid lubricant film. Surf Coatings Technol 2012; 206(24):5060-5066.

[8] Pacella M, Axinte DA, Butler-Smith PW, Shipway P, Daine M, Wort C. An assessment of the wear characteristics of microcutting arrays produced from polycrystalline diamond and cubic boron nitride composites. J Manu Sci and Eng 2015, 138 (2): 2100101-2100116.

[9] Pacella M. A new low-feed chip breaking tool and its effect on chip morphology. Int J Adv Manuf Technol 2019; 104(1-4):1145-1157.

[10] Pacella M, Butler-Smith PW, Axinte DA, Fay MW. FIB/TEM/EELS micro/nanometric investigations of the effects of laser ablation on the diamond/binder structure in polycrystalline diamond composites. J Mater Process Tech 2014; 214(5):1153-1161.

[11] Sugihara T, Enomoto T. Development of a cutting tool with a nano/micro-textured surface-Improvement of anti-adhesive effect by considering the texture patterns. Precis Eng 2009; 33(4):425-429.

[12] Kawasegi N, Sugimori H, Morimoto H, Morita N, Hori I. Development of cutting tools with microscale and nanoscale textures to improve frictional behaviour. Precis Eng 2009; 33(3):248-254.

[13] Sugihara T, Enomoto T. Improving anti-adhesion in aluminium alloy cutting by micro stripe texture. Precis Eng 2012; 36(2):229-237.

[14] Deng J, Lian Y, Wu Z, Xing Y. Performance of femtosecond laser-textured cutting tools deposited with WS2 solid lubricant coatings. Surf Coatings Technol 2013; 222:135-143.

[15] Ma J, Duong NH, Lei S. 3D numerical investigation of the performance of microgroove textured cutting tool in dry machining of Ti-6Al-4V. Int J Adv Manuf Technol 2015; 79(5-8)1313-1323.

[16] Greiner C, Schäfer M. Bio-inspired scale-like surface textures and their tribological properties. Bioinspir Biomim 2015; 10(4):440010-4400110.

[17] Chou YK, Evans CJ, Barash MM. Experimental investigation on cubic boron nitride turning of hardened AISI 52100 steel. J Mater Process Technol 2003; 134(1):1-9.

[18] Groover MP. Principles of Modern Manufacturing, 5th ed. Singapore: John Wiley \& Sons; 2013.

[19] Pacella M, Nekouie V, Badiee A. Surface engineering of ultra-hard polycrystalline structures using a nanosecond $\mathrm{Yb}$ fibre laser: effect of process parameters on microstructure, hardness and surface finish. J Mater Process Technol 2019; 266:311-328.

[20] Harris TK, Brookes EJ, Taylor CJ. The flow stress of PcBN cutting tool materials at high temperatures. Int J Refract Met Hard Mater 2001; 19(4-6):267-273.

[21] Pacella M. Pulsed Laser Ablation (PLA) of ultra-hard structures: generation of damage-tolerant freeform surfaces for advanced machining applications 2014. The University of Nottingham.

[22] Nakamoto T, Shamoto E, Yamazaki Y, Sirakata Y. Development of titanium boride grinding wheel by laser sintering. J JSME 2006; 72(716):370-375.

[23] Grzesik W. Advanced machining processes of metallic materials, $2^{\text {nd }}$ ed. Elsevier; 2017.

[24] Pacella M, Badiee A, Ghosh P. Laser micro-nano texturing of a polycrystalline ultra-hard cutting tool to improve wear behaviour. SPIE LASE Laser-based Micro and Nanoprocessing XIII 2019; 10906:17.

[25] Pacella M, Butler-Smith PW, Axinte DA, and Fay MW. The allotropic transformation of polycrystalline cubic boron nitride structures resulting from the thermal effects of pulsed laser ablation. Diam Relat Mater 2015; 59:62-68. 